\title{
Stenotrophomonas Maltophilia: Novel Biopolymer Producing Plant Pathogen
}

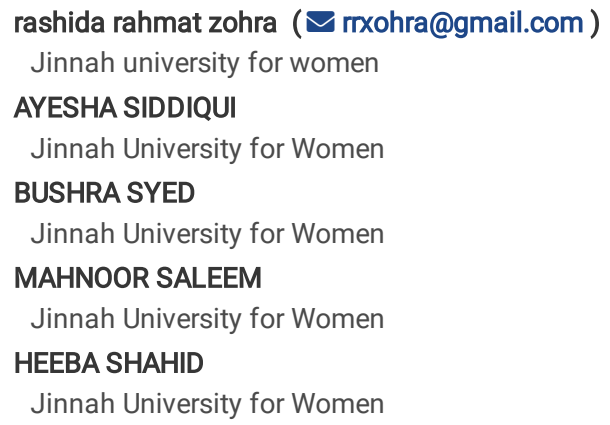

\section{Research Article}

Keywords: Biopolymer, Xanthan, Plant pathogen, Xanthomonadaceae, Fermentation, Physico-chemical parameter, 16s rRNA

Posted Date: May 6th, 2021

DOI: https://doi.org/10.21203/rs.3.rs-474691/v1

License: (c) (i) This work is licensed under a Creative Commons Attribution 4.0 International License. Read Full License 


\section{Abstract}

Biopolymers are making their way into the global market very rapidly owing to their biodegradability and environmentally friendly characteristics. Xanthan, a microbial polysaccharide is being produced by plant pathogens. It is widely used in numerous industrial applications. In the current study, plant pathogenic bacterial strains were isolated from infected plants and screened for biopolymer production. Several strains having higher yield of polymer were further subjected to the physicochemical and genomic analysis. The highest biopolymer producing strain Stenotrophomonas maltophilia X2 was found to be novel in commercial exploitation for biopolymer production. It was concluded that, the strain Stenotrophomonas maltophilia X2 can produce higher yield of biopolymer under static condition; in self formulated medium containing $5 \%$ sucrose at $\mathrm{pH} 7.0$ when incubated at $28^{\circ} \mathrm{C}$ for 120 hours.

\section{Introduction}

Increasing cost, depleting petro fuel and environmental concerns involved in the production of synthetic and natural polymers have kicked the search for alternative sources for polymer production. For this purpose, various bio-based materials have been explored for the production of biopolymers (Mohsin et al., 2018). The biopolymer can be extracted from microbial and plant sources or can be synthesized chemically from various biological materials (Katherine et al., 2017). Significant considerations has been given to the biopolymers produced by microbes as it is easy to scale up, environment friendly and yield high quality product (Katherine et al., 2017).

A variety of microbial polymers such as xanthan, dextran, levan, alginate, pullulan, cellulose have tremendous applications in industry (Ates, 2015). These biopolymers display diverse range of physic-chemical properties and add value to commercial products. Many of the biopolymers are polysaccharide in nature and are produced as extracellular metabolite which are purified and used in numerous pharmaceutical, medical, food and research applications. Among variety of different polysachharides, Xanthan is an exopolysaccharide of glucose, mannose, and glucuronic acid monomers, produced by Xanthomonas species. Mostly the molecular weight of the polymer ranges from $2 \times 10^{6}$ to $20 \times 10^{6} \mathrm{Da}$, however low molecular weight molecules have also been reported (Sajna et al., 2015).

The unique physicochemical characteristics of xanthan enables it to be largely used as stabilizers, thickener, emulsifier and in various industries like pharmaceutical, food and petroleum because of its additional friction reducing capabilities (Carignatto et al., 2011). The resistance of xanthan to broad range of temperatures, $\mathrm{pH}$ and salts also makes it suitable for variety of industrial applications. (Nasrsoudi et al., 2007).

Xanthan based products are in a surge and an estimate is that $10-15 \%$ innovative xanthan based products have been introduced into the market annually and the demand is increasing tremendously. (Khan et al., 2016).

Xanthomonas species are plant pathogens and causes leaf blight. The isolated bacterium produces copious amount of polymer when suitable conditions and nutritional requirements are met (Rosalam et al., 2008), (Borges et al., 2008), (Rosalam \& Vendruscolo, 2007). Different techniques are employed for the recovery of polymer including centrifugation, filtration, organic solvents and salts (Candia \& Deckwer, 2008, Palaniraj \& Jayaraman, 2008).

Current study was designed to explore the native xanthan producing microorganisms and their characterization for the production of polymer. The polymer obtained will be characterized and utilized in cosmaceutical formulations in future.

\section{Material And Methods}

\section{Culture media formulation}

A new culture medium was self-designed by modifying the media used by Rosalam et al., 2008 and Carignatto et al., 2011. Both the medias were studied and their effect were observed on standard strains of Xathnomonas campestris pv vesicatoria FCBP-PB-0003, Xathnomonas campestris pv mangiferae indica FCBP-PB-0003, obtained from First Fungal Culture Bank of Pakistan, Institute of Agriculture Sciences, University of Punjab, Pakistan and Xanthomonas campestris ICMP 8425, Xanthomonas campestris pv. campestris ICMP 21080 from Landcare Research Center NewZealand. The modified media, was named as Production Media (PM media).

Table 1

Composition of Nutrient Medium PM for xanthan production

\begin{tabular}{|lll|}
\hline S. No & Component & Production Media (gm/l) \\
\hline 01 & Sucrose & 50 \\
\hline 02 & Agar agar & 20 \\
\hline 03 & Yeast Extract & 20 \\
\hline 04 & K2HPO4 & 10 \\
\hline 05 & MgSO4 & 0.4 \\
\hline 06 & CaCO3 & 05 \\
\hline 07 & Bacto Peptone & 30 \\
\hline
\end{tabular}


Samples were collected from the diseased part of different plants leaves that were blighted. The infected plants of brassica family were sought from various parts of University of Karachi and local vegetable vendors. The samples were cut into small pieces and dipped in $70 \%$ ethanol to surface sterilize the leaves samples and then washed with sterile distilled water, air dried and placed the leaves pieces on PM media agar plate at $30^{\circ} \mathrm{C}$ for $24 \mathrm{hrs}$ (Borges et al., 2008). For culture purification, the bacterial cultures were re-streaked on fresh nutrient agar plate with $0.85 \%$ saline dilutions (Rosalam \& Vendruscolo, 2007 ). Among all the isolates, higher polymer producing strain X2 was subjected to optimization of physicochemical parameters and selected for further study.

\section{Biochemical characterization of strains}

Isolated biopolymer producing strains were identification based on morphological and biochemical analysis according to "Berge's Manual of Determinative Bacteriology" and "Microbiology a Laboratory Manual by Cappuccino James G Sherman" (Bergey \& Holt, 1993, Cappuccino and Sherman, 2002). The biochemical tests performed on the cultures included Gram's reaction, $\mathrm{KOH}$ string test, Starch hydrolysis, Tween 80 hydrolysis test, Citrate utilization, SIM (Sulfide, indole, motility) test, Catalase test and Urease test to differentiate between the Xanthomonadacea $s p$. and other biopolymer producing cultures.

Ribotyping and bioinformatics analysis: Phylogeny of the highest producing strains was confirmed by $16 \mathrm{~S}$ rDNA analysis using the protocol as described earlier R.R.Zohra (Zohra et al., 2008), and the obtained nucleotides sequence was submitted to GenBank, NCBI with the accession ID: MK422148. Furthermore, the phylogenetic tree of strain X2 was generated using software "MEGA-X (VERSION: X)" after the 16S rDNA analysis. Also, the timeline of the same bacterial strain was generated using the same software (Kumar, et al., 2018).

\section{Operational conditions for biopolymer production}

To get the maximum production of biopolymer, the inoculum was prepared by incubating the microbial strain for 24 hrs in PM media which is $5 \%$ of the volume of total fermentation media. Culture broth was then transferred into main fermentation flasks for further incubation and analysis of various fermentation parameters such as agitation, temperature, incubation period, $\mathrm{pH}$ and carbon concentration. All experiments were performed in triplicates (Candia \& Deckwer, 2008). Each factor was studied separately, one at a time and after the completion of incubation, culture broth was subjected to downstream processing for the recovery of biopolymer.

\section{Effect of incubation time}

To check the effect of incubation time on biopolymer production microbial strain was incubated in optimum growth medium and conditions from $24-192$ hrs.

\section{Effect of Sucrose concentration}

Isolated culture was inoculated in the production media by varying the sucrose concentration from $35-90 \mathrm{~g} / \mathrm{L}$. The inoculum was transferred to the main culture flask and incubated for $120 \mathrm{hrs}$ at optimized fermentation conditions.

\section{Effect of Temperature}

To optimize the temperature for maximum biopolymer production the culture was kept in the range of $25-40^{\circ} \mathrm{C}$ for $120 \mathrm{hrs}$ as recommended by Carignatto et al., 2011.

\section{Effect of $\mathrm{pH}$}

To optimize the $\mathrm{pH}$, the culture was checked in $\mathrm{PM}$ media in the $\mathrm{pH}$ range of $5-9$. To adjust the $\mathrm{pH}, 1 \mathrm{~N} \mathrm{NaOH}$ and $1 \mathrm{M}$ HCL were used before autoclaving the nutrient medium.

\section{Effect of Agitation}

To check the effect of agitation, inoculated flasks was incubated at shaking and non-shaking conditions at $30^{\circ} \mathrm{C}$ for 120 hours. The shaking was provided by keeping the culture flasks in orbital shaker at $80 \mathrm{rpm}$.

\section{Downstream processing of biopolymer}

Fermented culture medium was centrifuged after incubation at $10,000 \mathrm{rpm}$ for 4 minutes at $4^{\circ} \mathrm{C}$ to separate the biomass from broth. The supernatant recovered was saved for the recovery of biopolymer. The biomass settled in the pellet was dried at $55^{\circ} \mathrm{C}$ for $24 \mathrm{hrs}$ to remove the moisture (Freitas, et al., 2009 ).

To recover the biopolymer from cell free fluid, chilled ethanol was added in 1:3 ratio in the supernatant over constant stirring. The content was left at $-18^{\circ} \mathrm{C}$ (overnight) for complete recovery of the dissolved polymer from aqueous phase. Precipitates of biopolymer were separated from broth by centrifugation at $10,000 \mathrm{rpm}$ for 4 minutes. The supernatant was decanted and pellet obtained of the polymer was dried in hot oven at $55-60^{\circ} \mathrm{C}$ for $24-48$ hours. The amount of polymer recovered was estimated by the dry weight of the polymer per liter of the broth medium (Freitas, et al., 2009).

\section{Results And Discussion}

\section{Screening and characterization of polymer producing strains:}

In the present study 20 strains were isolated from the leaves of the plants that were blighted and produced yellow pigment demonstrating the occurrence of the species of the family Xanthomonadaceae. All the isolated plant pathogens were able to produce viscous polymer on nutrient agar and production media. However, only the yellow pigment producers were selected and recultured as Xanthomonadaceae family produce yellow pigmentation on nutrient agar and 
growth media (Borges et al., 2008, Candia \& Deckwer, 2008, Freitas, et al., 2009, Kumar, et al., 2018). Among the screened cultures, strain X2 showed the highest production and was selected for biopolymer production optimization studies (Fig. 1A).

\section{Biochemical characterization:}

Through phenotypic profiling and biochemical characterization, 8 strains were found to be gram negative and showed quite similar characteristics and were studied further for biochemical test analysis. However, some of the strains were slightly oxidase positive and $\mathrm{H}_{2} \mathrm{~S}$ negative unlikely as compared with the past literature of strains belonging to Xanthomonadaceas (Naqvi et al. 2012 and Arshad et al. 2013).

Table 2

Biochemical characterization of biopolymer producing plant pathogens

\begin{tabular}{|c|c|c|c|c|c|c|c|c|}
\hline Strain & $\begin{array}{l}\text { Strenotrophomonas } \\
\text { maltophilia strain } \\
X 2\end{array}$ & $\begin{array}{l}\text { Bacillus } \\
\text { cereus } \\
\text { strain X4 }\end{array}$ & $\begin{array}{l}\text { Strenotrophomonas } \\
\text { maltophilia strain } \\
X 7\end{array}$ & $\begin{array}{l}\text { Alcaligenes } \\
\text { faecalis } \\
\text { strain X10 }\end{array}$ & $\begin{array}{l}\text { Strenotrophomonas } \\
\text { sp. strain X12 }\end{array}$ & $\begin{array}{l}\text { Bacillus } \\
\text { cereus } \\
\text { strain } \times 14\end{array}$ & $\begin{array}{l}\text { Bacillus } \\
\text { sp. strain } \\
\text { X15 }\end{array}$ & $\begin{array}{l}\text { Strenotrophor } \\
\text { maltophilia st } \\
\text { X22 }\end{array}$ \\
\hline $\begin{array}{l}\text { Genbank } \\
\text { Accession }\end{array}$ & MK422148.1 & MK775363 & MK775463 & MK775526 & MK775529 & MK780189 & MK780182 & MK782051 \\
\hline $\begin{array}{l}\text { Gram's } \\
\text { reaction }\end{array}$ & - & - & - & - & - & - & - & - \\
\hline $\begin{array}{l}\text { Citrate } \\
\text { utilization }\end{array}$ & + & + & + & + & + & + & + & + \\
\hline Catalase & + & + & + & + & + & + & + & + \\
\hline Glucose & + & + & + & + & + & + & + & + \\
\hline Lactose & - & - & + & + & + & + & + & + \\
\hline Maltose & + & - & + & + & + & + & + & + \\
\hline $\begin{array}{l}\text { Starch } \\
\text { hydrolysis }\end{array}$ & + & + & + & + & + & + & - & + \\
\hline $\begin{array}{l}\text { Tween } 80 \\
\text { hydrolysis }\end{array}$ & + & + & - & - & + & - & + & - \\
\hline $\begin{array}{l}\text { Urea } \\
\text { utilization }\end{array}$ & + & + & - & - & - & + & + & - \\
\hline $\begin{array}{l}\text { Nitrate } \\
\text { reduction }\end{array}$ & - & + & + & - & + & + & + & - \\
\hline $\begin{array}{l}\mathrm{H} 2 \mathrm{~S} \\
\text { production }\end{array}$ & - & - & - & - & - & - & - & - \\
\hline Indole & - & - & - & - & - & + & + & - \\
\hline Motility & + & + & + & + & + & - & - & - \\
\hline MR & - & - & - & - & - & + & + & + \\
\hline VP & - & - & - & + & - & - & - & - \\
\hline $\mathrm{KOH}$ & + & + & + & + & + & + & + & + \\
\hline
\end{tabular}

\section{Bioinformatics analysis:}

All the strains were subjected to ribotyping and found to be belonging to different genera of bacterium (Table 2). Owing to high biopolymer production, Bacterial strain X2 was selected for further study on biopolymer production parameters rest of all strains were glycerol preserved for future studies. The strain X2 was characterized as Stenotrophomonas maltophilia belonging to family Xanthomonadaceae. 16S rDNA nucleotide sequence was compared with other related species sequences by using BLAST (https://blast.ncbi.nlm.nih.gov/Blast.cgi). It showed that the sequence is novel and similar to Stenotrophomonas maltophilia after multiple alignment. Nucleotide sequences of all strains were deposited in GenBank database and received accession number as listed in Table 2. This sequence of Stenotrophomonas maltophilia X2 (MK422148) was further analyzed by phylogenetic tree construction (Fig. 3).

The S. maltophilia strain X2 is genetically related to the Stenotrophomonas $s p$. strain X22. Basically, the Stenotrophomonas sp. strain X22 is genetically subdivided into two phylogenic nodes (categories), one of which gives rise to the strain $\mathrm{x} 12$. And the other node gives rise to the clad that bears $S$. maltophilia strain $X 7$ and S. maltophilia strain X9, which are genetically close to Stenotrophomonas sp. strain X12.

The other node (15) of Stenotrophomonas sp. strain X22 gives rise to the strain S. maltophilia strain X2, that are further subdivided to the strain A. faecalis strain $X 10, B$. cereus strain $X 4$, Bacillus sp. strain $X 15$ and $B$. thuringienesis strain $X 14$, on the basis of small genetic differences. In these sub divisions, Bacillus sp. strain $X 15$ and $B$. thuringienesis strain $X 14$ are likely similar to each other. Whereas, $B$. thuringienesis strain X14 and Bacillus sp. strain $X 15$ are likely similar to each other. The ancestor of strain $A$. faecalis strain $X 10$ is likely similar to strain $S$. maltophilia strain X2. On the other hand, $B$. cereus strain $X 4$ is similar to the ancestor of Bacillus sp. strain X15 and B. thuringienesis strain X14. 
Members of this species are known to display high genetic, ecological and phenotypic diversity, forming the so-called S. maltophilia complex (Smc). Heterogeneous resistance and virulence phenotypes have been reported for environmental Smc isolates of diverse ecological origin. According to the past literature regarding the phylogenic analysis of stenotrophomonas maltophilia, its genome is reported to have certain genetic matches with some species of bacillus and Geobacillus stearothermophilus strain KCB 2.

The evolutionary timeline of the Stenotrophomonas maltophilia X2 can be seen in Fig. 4 which reveals its presence in several ages and its biological features, including the fact that, this strain was first found 1733 MYA (Million Years Ago). The presence of this bacteria covered several geological periods comprising on, meso-proterozoic, neo-proterozoic, paleozoic and mesozoic periods. These geological timescales showed a great variation in the levels of oxygen, carbon dioxide and solar luminosity, that were acceptable for the growth of Stenotrophomonas maltophilia

\section{Optimization of Fermentation parameters}

Stenotrophomonas maltophilia X2 was studied for production and biopolymer recovery parameters. Physicochemical parameters such as incubation time, temperature, $\mathrm{pH}$, shaking/static and substrate concentration were analyzed one at a time. Each parameter was performed in a triplicate set.

\section{Effect of incubation time}

Incubation time is an important variable for biopolymer production. By varying the incubation period from 24 hrs to 192 hrs, it was found that at 120 hrs X2 yield highest biopolymer production and then gradual decrease was observed (Fig. 5). In the initial hours, the nutrients are expected to be maximally utilized for biomass increment; the polymer production being the secondary metabolite increased in later phases on incubation. After 120 hrs, the polymer production was found to be decreased which could be attributed to utilization of polymer as sugar reserve by the bacterium (Candia \& Deckwer, 2008).

\section{Effect of sucrose concentration}

Sucrose was used as carbon source in the media as reported in literature (Zohra et al., 2008). To investigate the appropriate amount of sucrose required to produce highest yield of xanthan, different concentrations were checked i.e. $3 \%, 5 \%, 7 \%$ and $9 \%$ respectively. The best biopolymer production by $\mathrm{X} 2$ was found at $5 \%$ and it was observed that the growth and biopolymer production started to restrict after $5 \%$ (Fig. 6 ). In the past literature sugar concentration higher than $6 \%$ had negative influence on xanthan production and viscosity and $2-4 \%$ of carbon source is preferred as high concentration of sucrose inhibits the bacterial growth (Caroline \& Claire, 2007, Swamy et al., 2012, Arshad et al., 2015)

\section{Effect of pH}

Fermentation process for biopolymer is slightly acidic because of the metabolism of nitrogen and sugar sources which produce various acids as end product (Zohra et al., 2008). The growth of cells is dependent on $\mathrm{pH}$, hence affecting the biopolymer production (Caroline \& Claire, 2007). The pH 7 was found to be sufficient for biomass and biopolymer production (Fig. 7). However, the pH below and above 7 were insufficient for the biomass and biopolymer production rate (Letisse et al., 2001, Bajaj et al., 2007, Kerdsup et al., 2009, Gumus et al., 2010, Soudi et al., 2011, Ozdal \& Kurbanoglu, 2018).

\section{Effect of agitation of fermentation media on biopolymer production}

It was concluded that, the bacterial cells were affected by mechanical agitation negatively and were best grown at static condition. The static incubation conditions for biomass and biopolymer production were found to be sufficient (Fig. 8). However, according to past literature biomass and biopolymer production increases within agitation fermentation condition (Freitas, et al., 2009). While in this study the agitation fermentation condition showed inverse relationship with the xanthan production using strain X2 (Caroline \& Claire, 2007, Soudi et al., 2011, Swamy et al., 2012).

\section{Effect of temperature}

The effect of temperature on biopolymer yield and growth of the organism were studied by optimizing the temperature between the ranges $25^{\circ} \mathrm{C}$ to $35^{\circ} \mathrm{C}$.Ideal temperature for biopolymer production from the results obtained was $30^{\circ} \mathrm{C}$ at which both the biomass and polymer yields were highest (Fig. 9). These results were in agreement with the past literature (Candia \& Deckwer, 2008, Gumus et al., 2010, Shu \& Yang, 2010).

\section{Downstream processing of biopolymer:}

Biopolymer produced by the strain in response to supplied nutrients and fermentation conditions can be recovered from various techniques like ultrafiltration, precipitating agent, and enzyme treatment. Because of the high viscosity of fermented medium it is difficult to separate xanthan gum from unwanted constituents. High viscosity of fermented medium leads to degradation of polysaccharide during centrifugation (Suresh \& Prasad., 2005). To be use as food additives it is necessary for xanthan gum to be free of biomass and recovery agents. Including separation of unwanted debris, it is also important not to effect the properties of xanthan gum, which can be effected adversely by heat treatment processes (Garcia, et al., 20000). It is a standard procedure for xanthan gum recovery to precipitate out polysaccharide using precipitating agent such as isoprapanol, isobutanol (Nasr, et al., 2007). Other oragnic solvents can also be used like methanol, ethanol, t-butanol and acetone (Palaniraj \& Jayaraman., 2011). Salts can also be used as precipitating agent in polyvalent forms(Pace \& Righelato, 1981).

Biopolymer produced by X2 strain was recovered using microbial cell separation and alcohol precipitation technique. After removing the cells by centrifigutaion, chilled ethanol was added into the cell free fluid (CFF) in an optimized ratio of 3:1 (ethanol:CFF). The mixture was then kept at -18-20 ${ }^{\circ} \mathrm{C}$ for efficient recovery of polymer. 
Centrifugation and drying the pellet in dry heat oven separated the polymer from the cell free fluid + alcohol suspension. Figure 10 shows the recovered polymer. It was observed that this scheme of polymer purification led to $40 \%$ recovery of the polymer from the fermentation broth.

\section{Conclusion}

In order to reduce the production cost and to improve the competitive position of biopolymers, microbes are the best source leaving behind the plant-derived polysaccharides and synthetic polymers. Among various biopolymers, xanthan gum has gained importance in pharmaceuticals, cosmetics, cleaners, food, paints and various other industries.

In the present study 08 strains were isolated from the leaves of the infected plants. It was observed that different genera of bacterium including fecal contaminants and soil borne were present which showed similar lesions on leaves and other parts of plant. One (01) best biopolymer producing culture was selected to study the operational conditions for optimum polymer production i.e. agitation, temperature, $\mathrm{pH}$, sugar concentration and incubation time. Highest production of biopolymer was found in the media containing $5 \%$ sucrose when culture was incubated at $30^{\circ} \mathrm{C}$ for $120 \mathrm{hrs}$ at static condition.

The isolated strain X2 showed homology with the 16S ribosomal RNA gene of the partial sequence of Stenotrophomonas sp. strain Ap10(MK824562.1), Bacterium strain BS1374 (MH890517.1), Bacterium strain BS1240 (MK824428.1) and Stenotrophomonas maltophilia strain IAE189 (MK414888.1). According to the originated timeline of the strain, the Stenotrophomonas maltophilia has capabilities to grow in an environment having different levels of oxygen, carbon dioxide and solar luminosities.

The isolated strain is novel of its kind and has not been exploited for biopolymer production so far at commercial level. The strain produces xanthan at low operational parameters, i.e. static or very low agitation with moderate temperature requirement. It grows and produce the polymer in condition easy to be managed at commercial settings. Further, studies to take up the strain at pilot scale production will validate it for commercial exploitations.

\section{Declarations}

\section{- Ethics approval and consent to participate:}

Not Applicable

\section{- Consent for publication:}

Not Applicable

\section{- Availability of data and materials:}

The rDNA sequence analyzed by ribotyping available in the GenBank repository, with an accession ID: MK422148 . weblink of dataset at GenBank Whereas rest of all data generated or analyzed during this study are included in this published article [and its supplementary information files]

\section{- Competing interests:}

The authors declare that they have no competing interests

\section{- Funding:}

The study was funded by Higher Education Commission of Pakistan under the Technology Development Fund program. Project\#TDF-102.

\section{- Authors' contributions:}

Rashida Rahmat Ideation and research study designing, DNA extraction, Ribotyping, Compilation of data, Result interpretation and supervision as Zohra Principal Investigator

Ayesha Siddiqui Downstream processing of polymer

Mahnoor Saleem Phylogenetic study, drafting and compilation of manuscript

Bushra Syed Production parameters optimization

Heeba Shahid Strain isolation and physic-chemical screening of the strains

All authors read and approved the final manuscript

\section{- Acknowledgements}

The authors acknowledge the contribution of Mr. Arbaz Adil, Manager Research, Office of Research Innovation and Commercialization (ORIC) at Jinnah University for Women for his support and guidance during the course of the study. The authors are also thankful to the Department of Biotechnology at Jinnah University for women for institutional support.

\section{References}


1. Arshad HMI, Naureen S, Saleem K, Ali S, Jabeen T, Babar MM (2015) Morphological and biochemical characterization of Xanthomonas Oryzae pv. Oryzae isolates collected from Punjab during 2013. Adv Life Sci 2:125-130

2. Ates $O$ (2015) Systems Biology of Microbial Exopolysaccharides Production. Front Bioeng Biotechnol 3:1-16. doi:10.3389/fbioe.2015.00200

3. Bikales N, Brown N, Kaplan D, Jensen D (1993) Technical Overview of Biopolymer Field. Making Materials Nature's Way. Office of Technology Assessment, Washington, Biopolymers

4. Bajaj BI, Survase S, Saudagar P, Singhal R (2007) Gellan Gum: Fermentative production, downstream processing and applications. Food Technol Biotechnol 45(4):341-354

5. Borges CD, Vendruscolo CT (2007) Xanthan synthesized by strains of xanthomonas campestris pvpruni: Production, viscosity and chemical composition. Biosci J 23(4):67-73

6. Borges CD, Moreira AS, Vendruscolo CT, Ayub MA (2008) Influence of agitation and aeration in xanthan production by Xanthomonas campestris pvpruni strain. Rev. Argent Microbiol 40(2):81-85

7. Carignatto CRR, Oliveira KSM, Gomes VM, Neto PO (2011) New Culture Medium to Xanthan Production by Xanthomonas campestris pv. Campestris. Indian J Microbiol 51(3):283-288

8. Caroline DG, Claire TV (2007) Xanthan synthesized strains of Xanthomonas campestris pvpruni: Production, viscosity and chemical composition. Biosci J 23(4):67-73

9. Freitas F, Alves VD, Pais J, Costa N, Oliveira C, Mafra L, Hilliou L, Oliveira R, Reis MA (2009) Characterization of an extracellular polysaccharide produced by a Pseudomonas strain grown on glycerol. Bioresour Technol 100(2):859-865

10. Garcia-Ochoa F, Santos VE, Casas JA, Gomez E (2000) Xanthan gum: production, recovery and properties. Elsev Biotechnol Adv 18(7):549-579

11. Gumus T, Demirci AS, Mirik M, Arici M, Aysan Y (2010) Xanthan gum production of Xanthomonas spp. isolated from different plants. Food Sci Biotechnol 19(1):201-206

12. Katherine RF, Muthukumaran C, Sharmila G, Kumar MN, Tamilarasan R, Jaiganesh R (2017) Xanthan gum production using jackfruit-seed-powder-based medium: optimization and characterization. 3 Biotech 7(4):248-258

13. Kerdsup P, Tantratian S, Sanguandeekul R, Imjongjirak C (2009) Xanthan production by mutant strain of Xanthomonas campestris TISTR 840 in raw cassava starch medium. Food bioprocess tech 4(8):1459-1462

14. Khan KAR, Naeem M, Ali A, Rehman N, Nawaz Z (2016) Assessment of guar and xanthan gum based floating drug delivery system containing mefenamic acid. Acta Pol Pharm 73(5):1287-1297

15. Kumar S, Stecher G, Li M, Knyaz C, Tamura K (2018) MEGA X: Molecular Evolutionary Genetics Analysis across computing platforms. Mol Biol Evol 35(6):1547-1549

16. Letisse F, Chevallereau P, Simon JL, Lindley ND (2001) Kinetic analysis of growth and xanthan gum production with Xanthomonas campestris on sucrose, using sequentially consumed nitrogen sources. Appl Microbiol Biotechnol 55(4):417-422

17. Luvielmo MM, Borges CD, Toyama DO, Vendruscolo CT, Scamparini ARP (2016) Structure of xanthan gum and cell ultrastructure at different times of alkali stress. Braz J Microbiol 47(1):102-109

18. Mirik M, Demirci A, Arici M (2011) Xanthan gum production under different operational conditions by Xanthomonas axonopodis pv vesicatoria isolated from pepper plant. Food Sci Biotechnol 20(5):1243-1247

19. Mohsin A, Zhang K, Hu J, Salimurrehman, Tariq M, Zaman WQ, Khan IM, Zhuang Y, Guo M (2018) Optimized biosynthesis of xanthan via effective valorization of orange peels using response surface methodology: A kinetic model approach. Carbohydr Polym 181:793-800

20. Mudoi P, Bharali P, Konwar BK (2013) Study on the effect of pH, temperature and aeration on the cellular growth and Xanthan production by Xanthomonas campestris using waste residual molasses. J Bioproces Biotechniq 3(2):1-6

21. Nasrsoudi MR, Haghighi M (2007) Xanthan production by a native strain of X. campestris and evaluation of application in EOR. Pak J Biol Sci 10(17):3010-3013

22. Ozdal M, Kurbanoglu EB (2018) Valorisation of chicken feathers for xanthan gum production using Xanthomonas campestris MO-03. J Genet Eng Biotechnol 16(2):259-263

23. Palaniraj A, Jayaraman V (2011) Production, recovery and applications of xanthan gum by Xanthomonas campestris. J Food Eng 106(1):1-12

24. Psomas SK, Kyriakides ML, Kyriakidis DA (2007) Optimization study of xanthan gum production using response surface methodology. Biochem Eng J 35(3):273-280

25. Rosalam S, Krishnaiah D, Bono A (2008) Cell free xanthan gum production using continuous recycled packed fibrous-bed bioreactor-membrane. Malays J Microbiol 4(1):1-5

26. Sajna KV, Gottumukkala LD, Sukumaran RK, Pandey A (2015) White Biotechnology in Cosmetics. In: Pandey A, Höfer R, Taherzadeh M, Nampoothiri KM, Larroche $C$ (eds) Industrial Biorefineries and White Biotechnology. Elsevier

27. Shu CH, Yang ST (1990) Effects of temperature on cell growth and xanthan production in batch cultures of Xanthomonas campestris. Biotechnol Bioeng 35(5):454-468

28. Soudi M, Alimadadi N, Ghadam P (2011) Minimal phenotypic test for simple differentiation of Xanthomonas campestris from other yellow-pigmented bacteria isolated from soil. Iran J Microbiol 3(2):84-91

29. Swamy MK, Khan BA, Rohit KC, Purushotham B (2012) Effect of carbon and nitrogen sources on the production of Xanthan gum from Xanthomonas campestris isolated from soil. Arch Appl Sci Res 4(6):2507-2512

Page $7 / 12$ 
30. Zohra RR, Aman A, Ansari A, Haider MS, Qader SAU (2015) Production, characterization and end product analysis of dextran degrading endo dextranase from Bacillus licheniformis KIBGE-IB25. Int J Biol Macromol 78:243-248

\section{Figures}

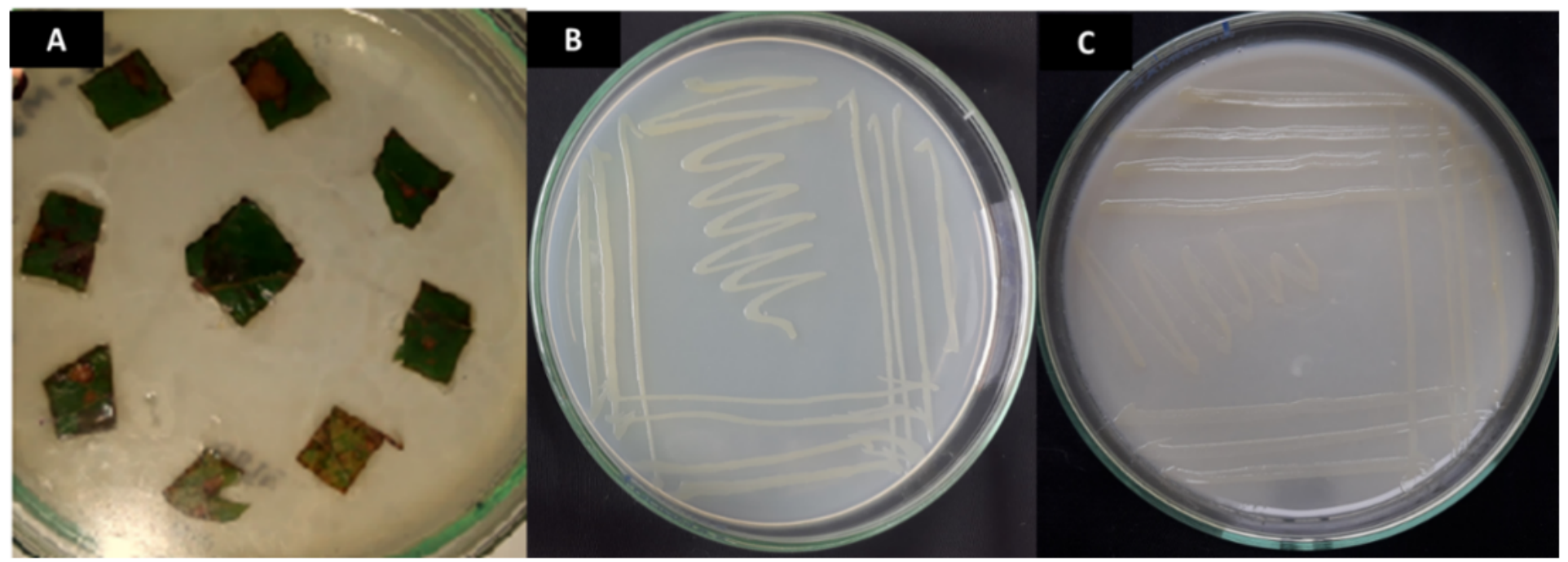

\section{Figure 1}

Infected leaves plating (A), Growth of Strenotrophomonas maltophilia strain X2 on nutrient agar (B) Growth of Strenotrophomonas maltophilia strain X2 on production agar plates.

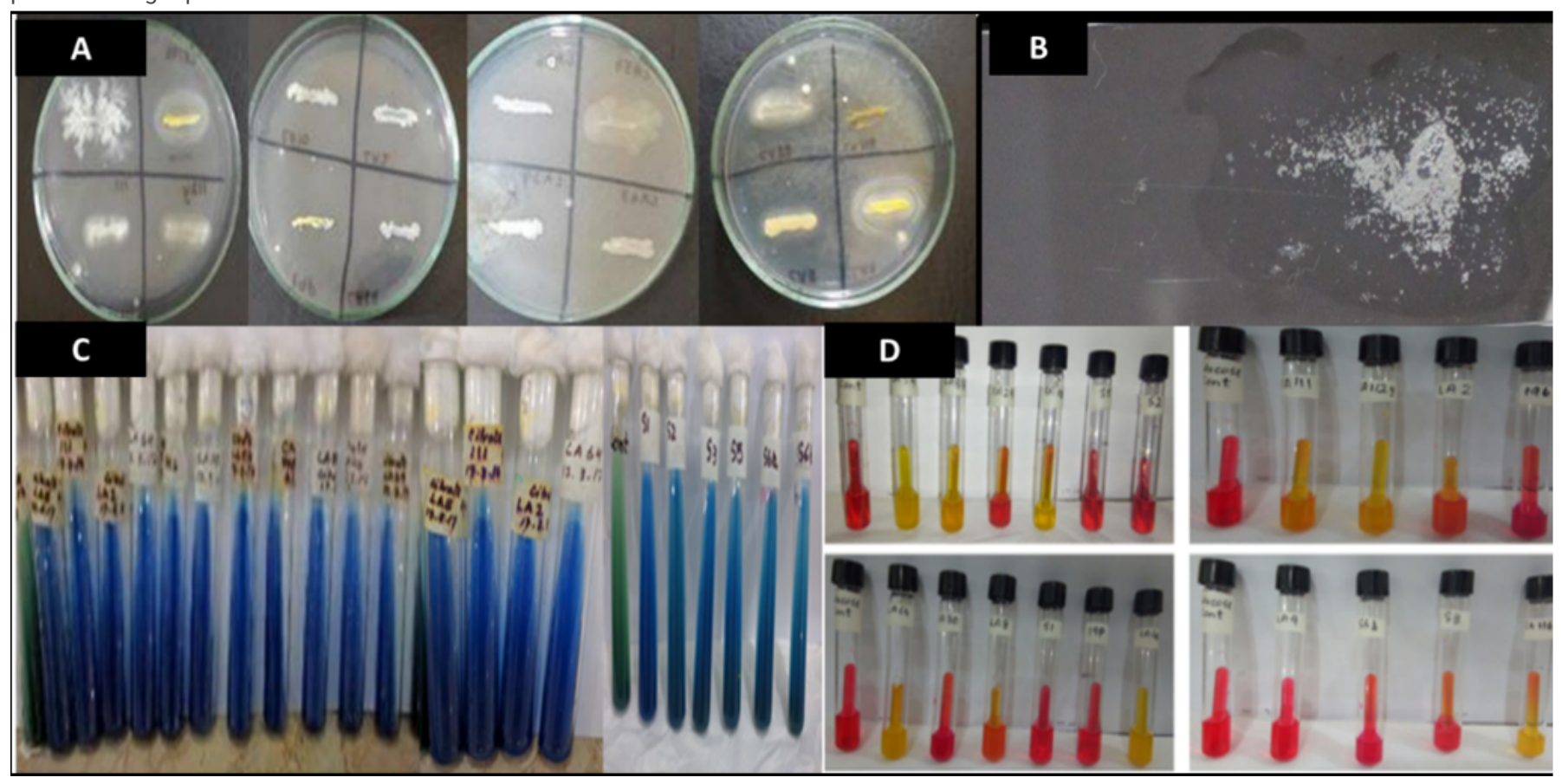

Figure 2

Plate assay of Tween 80 hydrolysis (A), Catalase test, Bubbles formation (B), Change in color indicating the utilization of citrate (C), Glucose fermentation indicated by change in color (D) 


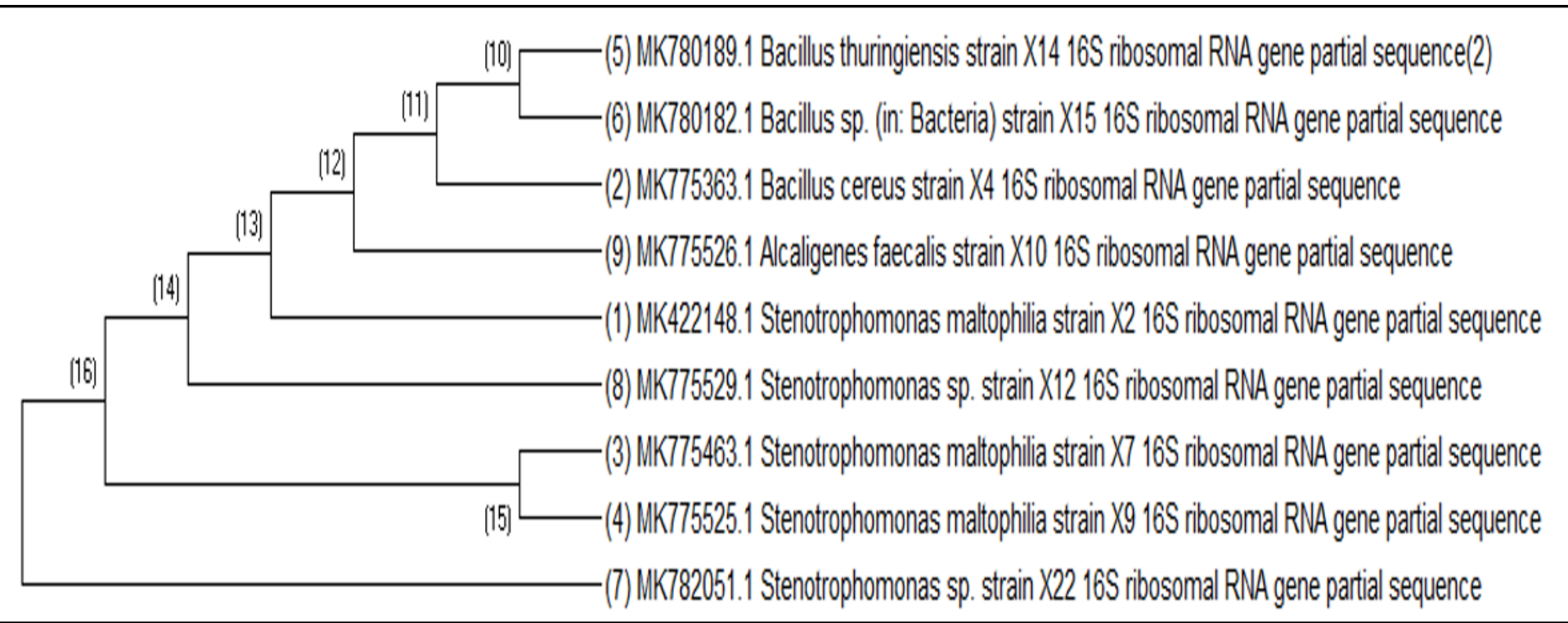

Figure 3

Phylogenetic tree of Stenotrophomonas maltophilia X2 (Accession\# MK422148) (Kumar, et al., 2018).

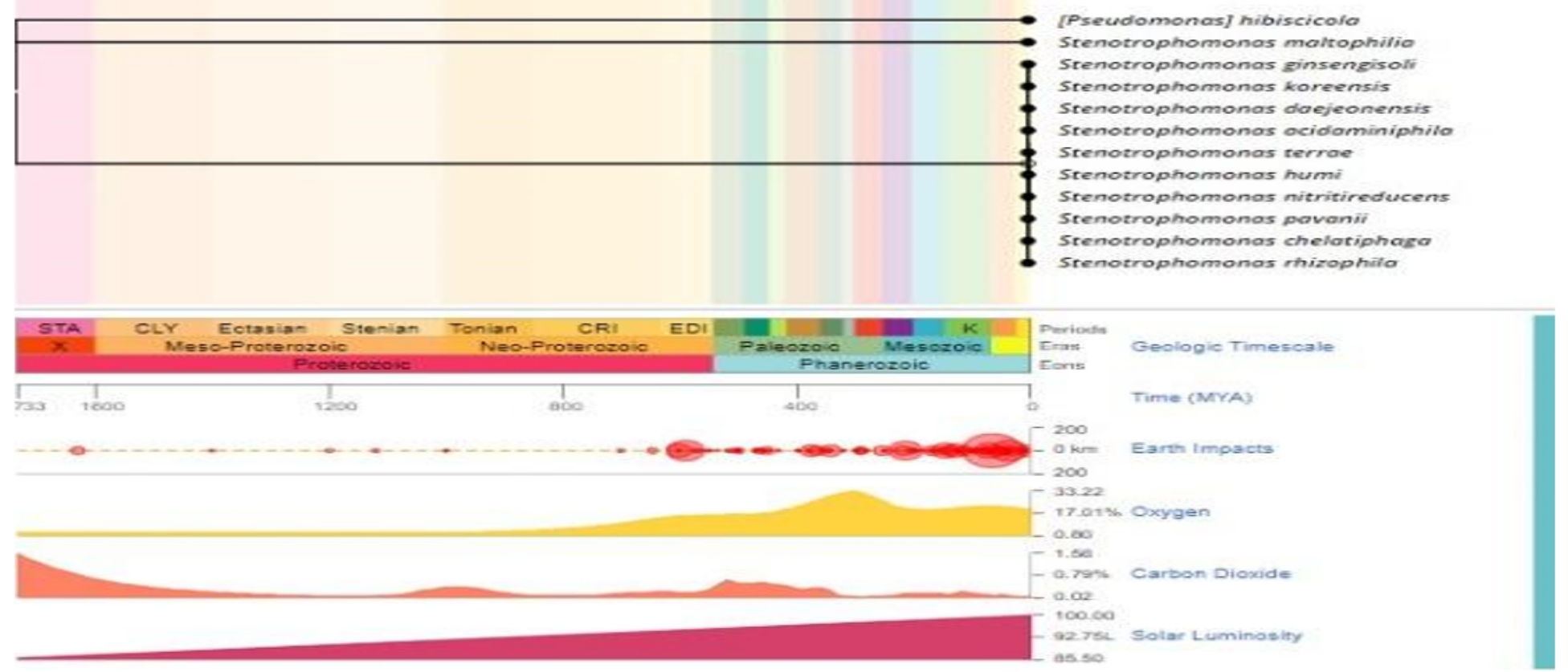

Figure 4

Timeline of Stenotrophomonas maltophilia. (Kumar, et al., 2018). 


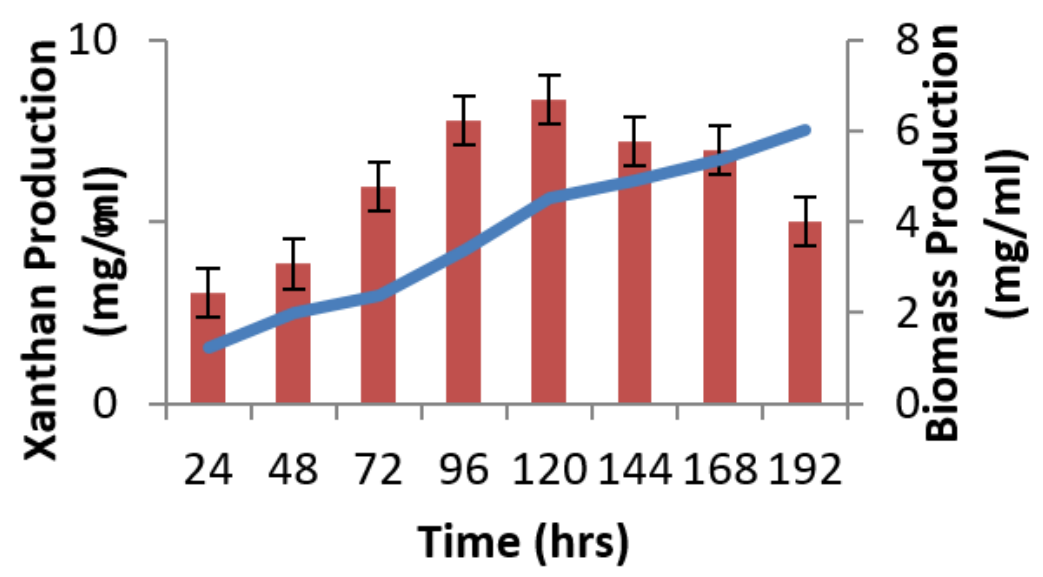

Xanthan Production

Biomass Production

Figure 5

Production of xanthan at different time course

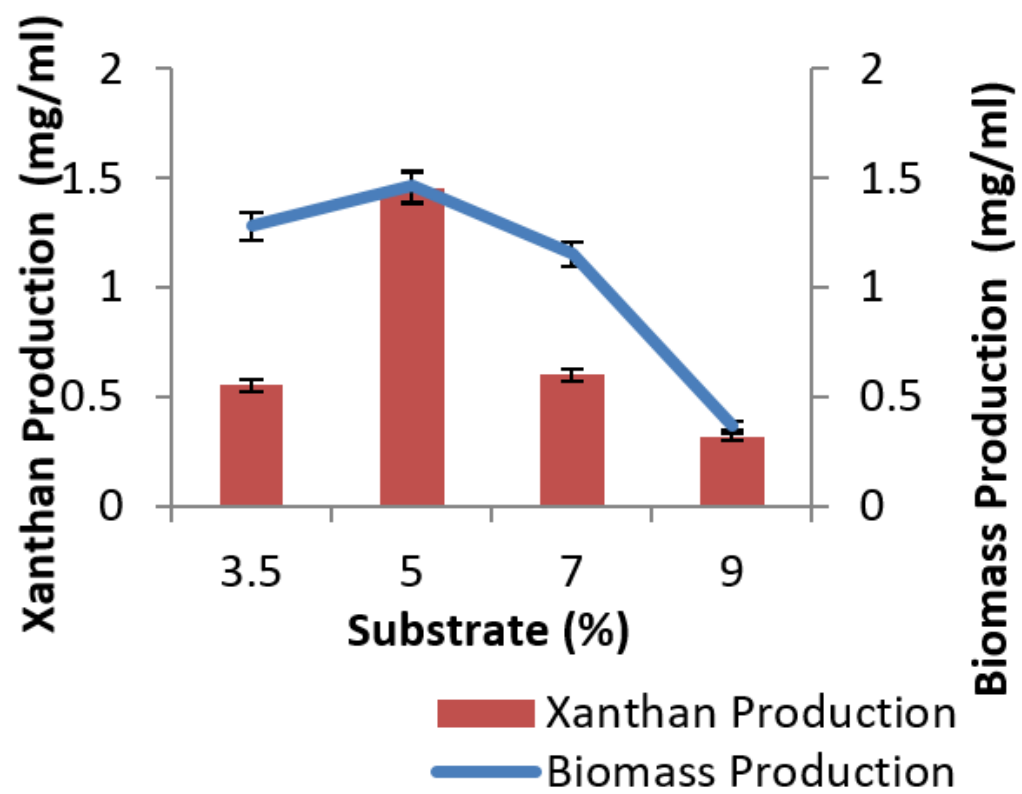

Figure 6

Production of xanthan at different substrate concentration 


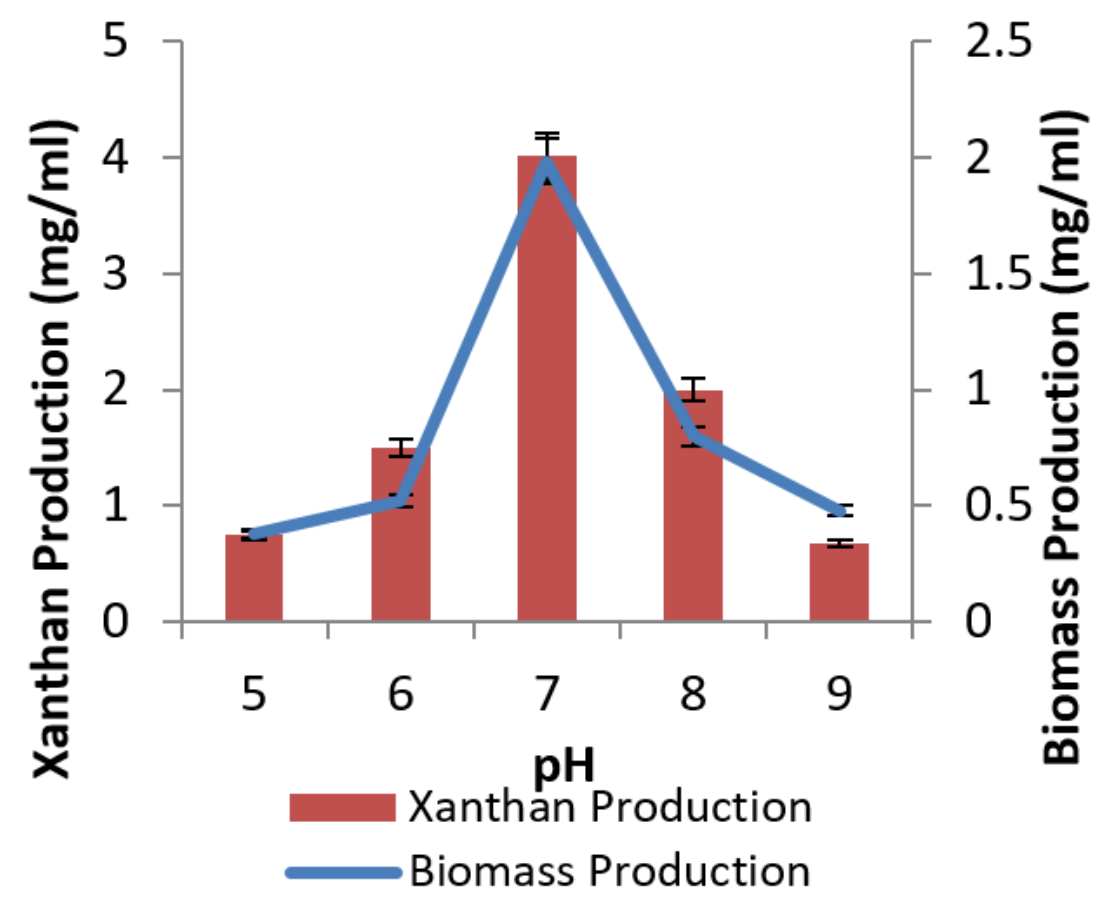

Figure 7

Production of xanthan at different $\mathrm{pH}$

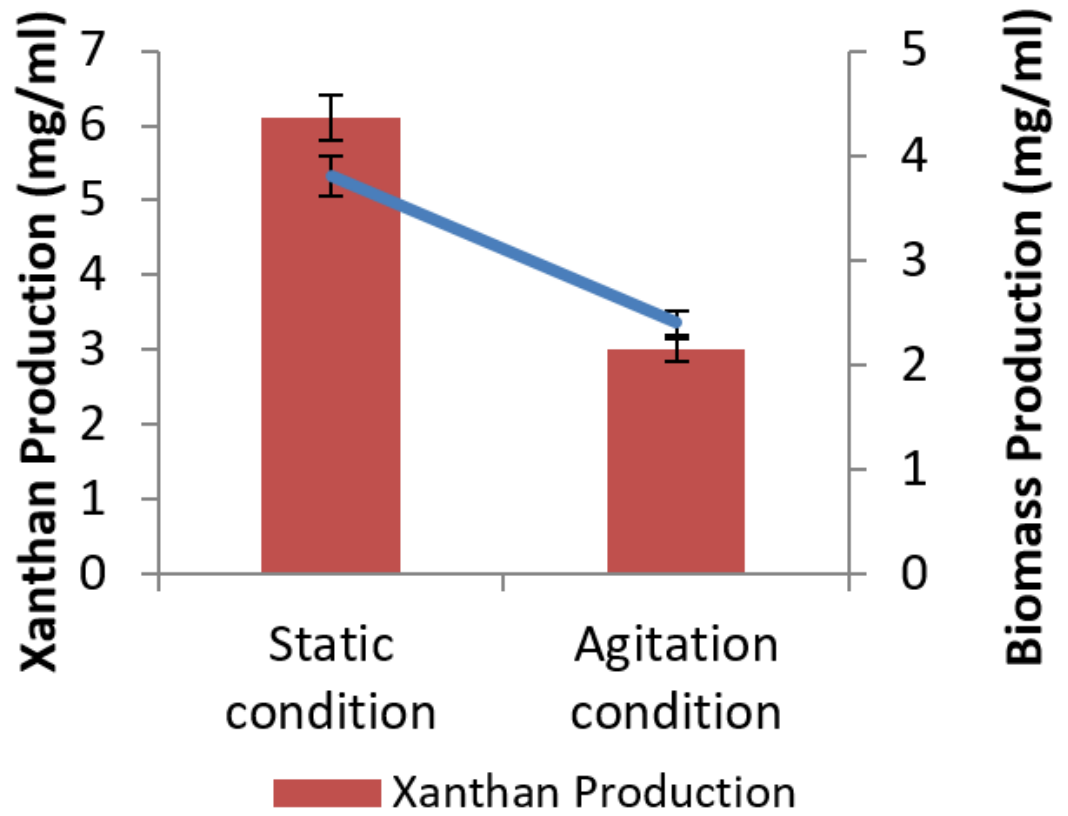

Figure 8

Production of xanthan at different growth conditions 


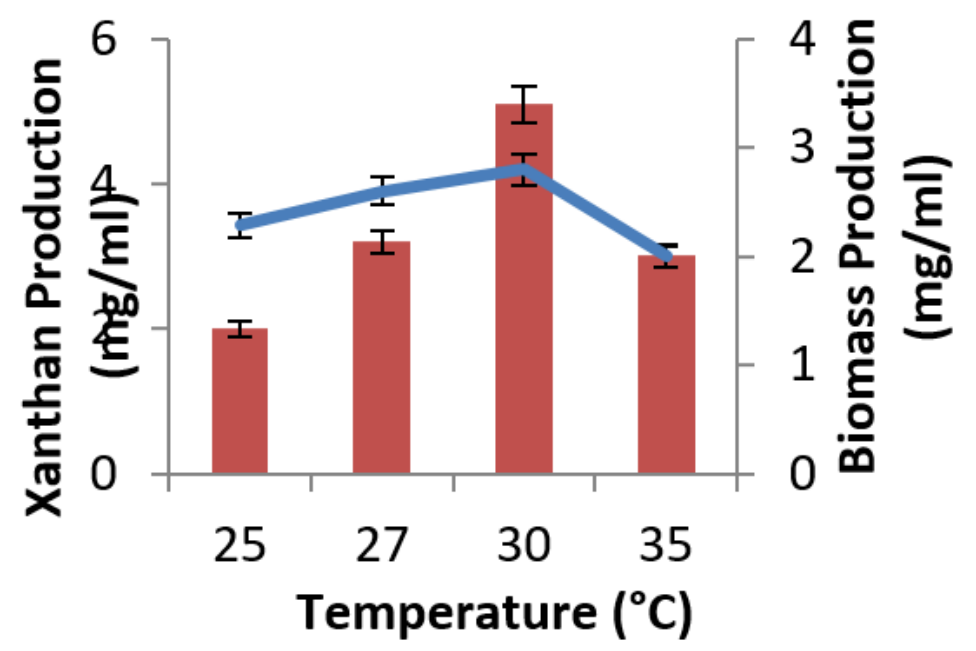

Xanthan Production

Biomass Production

Figure 9

Production of xanthan at different temperatures

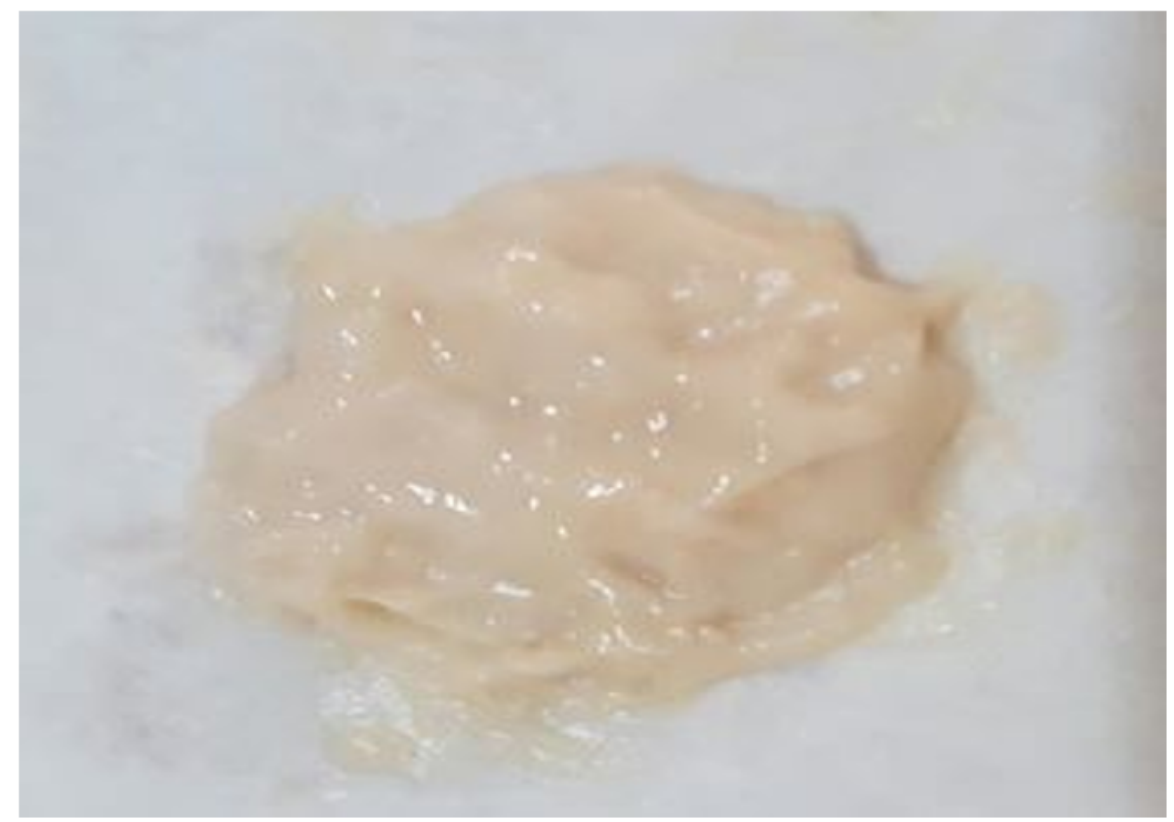

Figure 10

Extracted xanthan gum after purification

\section{Supplementary Files}

This is a list of supplementary files associated with this preprint. Click to download.

- graphicalabstarct.tif 